\title{
Nitric Oxide Molecule as A Potential Target of Alternative Strategies for the Diagnosis of
} Subclinical Mastitis in Cows

Canan GULMEZ ${ }^{*}$, Onur ATAKISI ${ }^{2}$

\begin{abstract}
The mastitis is an important disease affecting daily milk yield and quality in lactating cows, it negatively affects both animal welfare and economic income. The aim of this study is to investigate the effect of subclinical mastitis on nitric oxide (NO), total antioxidant capacity (TAC), total oxidant capacity (TOC), albumin, total protein, globulin, glucose and gamma glutamyl transpeptidase activity (GGT) levels in plasma. The research was carried out in Brown Swiss and Holstein cows. The mammary lobes of the animals were scanned with the California Mastitis Test (CMT) and those with subclinical mastitis were identified. Samples with CMT (-) were classified as healthy $(\mathrm{n}=10)$ and those with CMT (+) were classified as subclinical mastitis group $(\mathrm{n}=10)$. The study presented is a basic feature and results clearly showed that significant amounts of NO was released in plasma during subclinical mastitis. There was no statistically significant difference between cows with or without subclinical mastitis for plasma TAC, TOC, albumin, total protein, globulin, glucose, albumin/globulin levels and GGT activity. Consequently, nitric oxide is an important mediator in subclinical mastitis as a potential target of therapeutic strategies and can be evaluated in alternative diagnosis.
\end{abstract}

Keywords: Subclinical mastitis, Cow, Nitric oxide

${ }^{1}$ Canan GULMEZ (Orcid ID: 0000-0003-3253-1407), Department of Pharmacy Services, Tuzluca Vocational High School, Igdir University, Igdir-Turkey

2 Onur ATAKISI (Orcid ID: 0000-0003-1183-6076), Department of Chemistry, Faculty Science and Letter, Kafkas University, Kars-Turkey

*Corresponding Author: Canan GULMEZ, e-mail: canan_glm@ hotmail.com 


\section{INTRODUCTION}

Mastitis, defined as an "inflammation of the mammary gland", decreases milk yield and quality in lactating cows. Since mastitis is an important disease affecting daily milk yield, it negatively affects both animal welfare and economic profit. Also, it has a high treatment cost and high culling rate (Seegers et al., 2003) While clinical mastitis is easily identified (changes in milk visible in the dark-bottomed mug test), subclinical mastitis is diagnosed with California Mastitis Test (CMT) as well as somatic cell counts in milk (Brito et al., 2006).

Currently, there are limited number of effective treatment options involving the use of antibiotics, and most bacteria (Escherichia coli, staphylococci, and streptococci etc.) that causes mastitis have been found to be resistant to drugs used in farms. In two different studies using ceftiofur hydrochloride in the treatment of clinical and subclinical mastitis, $70 \%$ and $65.8 \%$ of the cows recovered, respectively (Cortinhas et al., 2016; Regev et al., 2018; Zduńczyk and Janowski, 2020). In most countries, milk is allowed to sell when antibiotic residues are zero or too low. When the literature is examined, antibiotic residues were found in milk for a certain period of time after ceftiofur application (Neto et al., 2015; Cristina et al., 2010). The duration of antibiotic therapy, along with the milk withdrawal period, can cause milk loss for about 6-10 days and worsen economic losses (Bhosale et al., 2014; Conzuelo et al., 2013).

Excessive amounts of neutrophils, macrophages, lymphocytes and eosinophils are produced in milk as a response of mammary tissue to microorganisms. Increased levels of tumor necrosis factoralpha, interleukin-1 $\beta$, interleukin 6 , interleukin 8 (TNF- $\alpha$, IL-1 $\beta$, IL-6, IL-8) and nitric oxide (NO) have been reported during infection. Nitric oxide is a signaling molecule that has important roles in biological systems. It has been shown to act as an endocrine molecule in recent years (Simontacchi et al., 2013). NO produce in higher amount during inflammation by inducible nitric oxide synthase (iNOS) and activated by cytokines, known as primer defense system (Lee et al., 2017). During inflammation, NO increases and reacts with superoxide anions leading to formation of peroxinitrite radical (Beckman et al., 1990) and free radicals (Pryor and Squadrito, 1997). Oxidative stress occurs when the balance between antioxidant and oxidant system changes in favor of oxidants. The oxidative stress has been observed in pneumonia, sepsis and mastitis diseases in farm animals and rodents. Free radicals that causes oxidative stress are produced in inflammation and oxidative reactions and accumulate in cells and tissues, thereby causing injury (Lykkesfeldt and Svendsen, 2007; Basu and Eriksson, 2001; Ilgun et al., 2016). In this sense, early diagnosis and treatment of mastitis is important as it will minimize economic losses. The aim of this study is to investigate the effect of subclinical mastitis on some biochemical parameters including NO, total antioxidant capacity (TAC), total oxidant capacity (TOC), albumin, total protein, globulin, glucose and gamma glutamyl transpeptidase activity (GGT) in circulating blood and to evaluate the potential of these parameters to be a marker for the early diagnosis of mastitis in cows.

\section{MATERIAL AND METHODS}

The research was carried out in Brown Swiss and Holstein cows, which were housed under the same feeding and stable conditions at Atatürk University, Veterinary Faculty, Research and Training Farm. First, the mammary lobes of the animals were scanned with the California Mastitis Test (CMT) and those with subclinical mastitis were identified. Samples with CMT (-) were classified as healthy (n $=10)$ and those with CMT $(+)$ were classified as subclinical mastitis group $(\mathrm{n}=10)$. Blood samples were taken from the animals into EDTA tubes and their plasma was obtained by centrifugation at $3000 \mathrm{rpm}$ 
for 15 minutes. Samples were stored at $-20^{\circ} \mathrm{C}$ until to be assayed. Total antioxidant and total oxidant capacity levels, albumin, total protein, glucose and NO levels and GGT activity were determined calorimetrically in the plasma samples. All chemicals and reagent were analytical grade products from Sigma (St. Louis, MO, USA).

\section{Biochemical analysis}

\section{Determination of total antioxidant (TAC) and total oxidative capacity (TOC) levels}

The TAC and TOC in the samples were determined as colorimetric (PowerWave XS, BioTek, Instruments, USA) with the commercial kit (Rel Assay, Mega Tip San.Tic.Ltd.Sti., Gaziantep, Turkey). The principle of total antioxidant capacity measurement is based on the decolorization of the 2,2'-azinobis (3-ethylbenzothiazoline-6-sulfonic acid) diammonium salt (ABTS) in the dark green color of the antioxidant substances present in the samples. The absorbance change of the samples at $660 \mathrm{~nm}$ varies in proportion to the concentration of antioxidants. The principle of total oxidant capacity measurement is based on the oxidation of the oxidant molecules in the samples to the ferrous ion-chelate complex to the ferric ion and measuring the color formed at $530 \mathrm{~nm}$. Trolox and hydrogen peroxide in total oxidant capacity was used as standard for total antioxidant capacity in (Erel, 2015).

\section{Nitric oxide (NO) assay}

Plasma NO levels, Miranda et al. (2001) measured colorimetrically. Firstly, the samples were treated with $10 \%$ zinc sulfate and proteins were removed. The nitrate contained in the samples was converted to nitrite with vanadium (III) chloride. It is based on the principle of the formation of the diazonium compound, based on the color formed by the reaction of sulfanilamide with N- (1-Naphtyl) ethylenediamine dihydrochloride in acidic medium. Different concentrations of nitrate and nitrite were used as standard in the measurements.

\section{Determination of levels of plasma glucose, total protein, albumin, globulin and gamma glutamyl transpeptidase activity}

The glucose, total protein, albumin levels and gamma glutamyl transpeptidase activity in plasma samples were determined using commercial kits via colorimetrically (TML $®$, Ankara, Turkey). The globulin concentration was calculated by subtraction of the albumin value from the total protein value.

\section{Statistical analysis}

Statistical analyses were performed in triplicate and average values with standard deviation (mean $\pm \mathrm{SD}$ ) are reported. Biochemical parameters were analyzed by ANOVA followed by post hoc Tukey test using SPSS 16.0 software package (SPSS ver. 16.0 for windows professional edition). Values were considered statistically significant if $\mathrm{P}$ value was less than 0.05 .

\section{RESULTS}

The NO, TAC, TOC, albumin, total protein, glucose levels and GGT activity in plasma samples were investigated (Table 1). There was no statistically significant difference between plasma total antioxidant and total oxidant capacity, albumin, total protein, globulin, glucose and albumin/globulin levels and GGT activities of healthy and with subclinical mastitis cows. Nitric oxide levels were significantly $(\mathrm{P}<0.05)$ higher in plasma samples with subclinical mastitis group compared to healthy group. It was $9.32 \mu \mathrm{mol} \mathrm{L}-1$ in the healthy group and $14.54 \mu \mathrm{mol} \mathrm{L}^{-1}$ in subclinical mastitis. 
Table 1. Plasma NO, TAC, TOC, albumin, total protein, globulin, glucose levels and GGT activity in healthy cows and cows with subclinical mastitis.

\begin{tabular}{|c|c|c|c|}
\hline Parameters & Healthy & Subclinical mastitis & $\mathbf{P}$ \\
\hline Nitric oxide $\left(\mu \mathrm{mol} \mathrm{L}{ }^{-1}\right)$ & $9.32 \pm 1.30$ & $14.54 \pm 1.94$ & $\mathrm{P}<0.05$ \\
\hline TAC (mmol Trolox Equiv. $\left.\mathrm{L}^{-1}\right)$ & $0,519 \pm 0,11$ & $0,464 \pm 0.057$ & Ns \\
\hline TOC $\left(\mu \mathrm{mol} \mathrm{H}_{2} \mathrm{O}_{2}\right.$ Equiv. $\left.\mathrm{L}^{-1}\right)$ & $0,215 \pm 0,045$ & $0,185 \pm 0,053$ & Ns \\
\hline GGT $\left(\mathrm{U} \mathrm{L}^{-1}\right)$ & $15,84 \pm 0.507$ & $16.0 \pm 1.15$ & Ns \\
\hline Albumin $\left(\mathrm{g} \mathrm{dL}^{-1}\right)$ & $3,81 \pm 0.056$ & $3,69 \pm 0.77$ & Ns \\
\hline Total Protein $\left(\mathrm{g} \mathrm{dL}^{-1}\right)$ & $6,66 \pm 0.12$ & $6,91 \pm 0.14$ & Ns \\
\hline Globulin $\left(\mathrm{g} \mathrm{dL}^{-1}\right)$ & $2.97 \pm 0.13$ & $3.10 \pm 0.17$ & Ns \\
\hline Albumin/Globulin $\left(\mathrm{g} \mathrm{dL}^{-1}\right)$ & $1.27 \pm 0.082$ & $1,26 \pm 0.078$ & Ns \\
\hline Glucose $\left(\mathrm{mg} \mathrm{dL}^{-1}\right)$ & $56.77 \pm 1.18$ & $55.74 \pm 1.79$ & Ns \\
\hline
\end{tabular}

Ns: Non significant

\section{DISCUSSIONS}

We used the subclinical mastitis model to investigate the possibility that nitric oxide acts as an inflammatory mediator in this disease (Ingman et al., 2014). Also, the effects of subclinical mastitis in cows on some biochemical parameters were examined. The study presented is a basic feature and results clearly showed that 1) significant amounts of NO are released during subclinical mastitis; 2) subclinical mastitis did not cause a change in levels of plasma TAC, TOC, albumin, total protein, globulin, glucose and GGT activity.

Nitric oxide is a molecule that is produced significantly from mammary gland epithelial cells and macrophages during inflammation and regulates many biological processes. In the endotoxin-induced mastitis model, an increased nitric oxide level in milk was noted as the response of the mammary gland to inflammation. The NO was reported to affect the release of prostaglandin and leukotrienes by bovine mammary gland during experimentally induced mastitis in vivo and in vitro (Piotrowska-Tomala et al., 2015) It has been stated that nitric oxide production increases in cows $(n=15)$ with endotoxin-induced mastitis and this increase is due to the activity of the inducible form of nitric oxide synthase in the inflammatory response process (Bouchard et al., 1999). In the study in which 15 cows with clinically mastitis and 25 cows subclinical mastitis were examined, it was observed that milk IL-6, lysozyme and nitric oxide levels increased in both groups compared to the control. The milk nitric oxide levels of control, subclinical and clinical mastitis groups was 5.59, 6.23 and $11.51 \mu \mathrm{M} \mathrm{mL}^{-1}$, respectively (Osman et al., 2010).

Silanikove et al. (2014) reported that milk nitrite, nitrate and S-nitrosamine levels increased significantly in goats $(\mathrm{n}=15)$ with subclinical mastitis compared to control. In another study, production, composition and milk quality of healthy and with subclinical mastitis was investigated. It was recorded that milk nitrite/nitrate levels increased in sheep with mastitis. (Alba et al., 2019). Atakisi et al. (2010) found that milk NO level and TOC increased in Brown Swiss and Holstein breed cows with subclinical mastitis $(n=35)$. The milk nitric oxide levels were determined 3.96 and $8.89 \mu \mathrm{mol} \mathrm{L}^{-1}$ in healthy and subclinical mastitis cows, respectively. In the current study, it was reported that plasma nitric oxide levels increased significantly in cows with subclinical mastitis. These levels for control and subclinical mastitis groups were 9.32 and $14.54 \mu \mathrm{mol} \mathrm{L}^{-1}$, respectively. In this sense, changes in nitric oxide level have the potential for alternative diagnosis of subclinical mastitis during inflammation.

During inflammation, NO reacts with superoxide ions, which leads to the formation of peroxynitrile radicals, and these radicals cause lipid peroxidation and formation of free radicals. Acute 
phase response is a response to inflammation, tissue injury and immunological disorders in an organism and is characterized by many physiological processes including metabolic and systemic changes. Acute phase proteins, which are the most important components in the response, are very important in the diagnosis, evaluation, treatment and prognosis of various diseases, including inflammation-related diseases. The function of the acute phase proteins (APPs) released in response to inflammation is to prevent free radical scavenging, oxidation of lipids, binding bacterial components and preventing microbial growth. Total protein, albumin, and globulin are some of the APPs (Tuthova et al., 2014). The inflammation profile of cows with subclinical and clinical mastitis was characterized by an increase in acute phase proteins (Serum amyloid A, haptoglobin, complement C3, serpin A3-1, vitronectin) and a decrease in antioxidative and anti-inflammatory proteins (PON1, PAF-AH, apoA-I, complement factor H, C4b-binding protein alpha chain) (Turk et al., 2012). Recently, the active immune response has been recognized to increase glucose demand by the immune system., During mastitis, the use of glucose for both immune system functions (production of reactive oxygen species (ROS) and antibodies) and milk synthesis in the activated immune cells reduces the amount of substrate (glucose, amyloid A). Substrate competition is an important mechanism that reduces milk yield in mastitis (Enger 2019).

It was recorded that milk ROS levels increased in mastitis group. There was no statistically significant difference between serum glucose, total protein, globulin, albumin and ROS levels in control and mastitis groups (Alba et al., 2019). Nedic et al. (2019) show that TAC levels were lower in blood serum and milk serum of cows from subclinical mastitis group $(n=55)$ compared to control group. It has been reported that mastitis also causes changes in saliva biomarkers of cows that reflect inflammation and oxidative stress in animals. When the control and mastitis groups were compared, it was shown that FRAP (ferric reducing ability of plasma) and CUPRAC (cupric reducing antioxidant capacity) methods, which are the methods of determining total antioxidant capacity, did not change salivary levels, while the serum CUPRAC level was low in the mastitis group. In addition, there was no statistically significant difference in total protein levels between both groups (Contreras-Aguilar et al., 2019). In this study, there was no statistically significant difference between plasma total antioxidant and total oxidant capacity, albumin, total protein, globulin, glucose and albumin/globulin levels of healthy and with subclinical mastitis cows. Usually, alanine aminotransferase (ALT), aspartate aminotransferase (AST), alkaline phosphatase (ALP) and GGT enzymes are used to evaluate the functions of the liver. The levels of these enzymes are used as an indicator of damage in a spectrum ranging from inflammation to necrosis rather than indicating liver function (Giannini et al., 2005). In the presented study, there was no statistically significant difference between plasma GGT activity levels of healthy and with subclinical mastitis cows.

In three different in vitro and in vivo (cows and cattle) experiments, where nitric oxide-releasing solution (NORS) can be used as a potential antimicrobial treatment tool for bovine mastitis, NORS was lowered the bacterial concentration in all infected samples, in a time and milk-diluted dependent fashion. Also, the blood and milk nitrite concentrations was increased initially but, during the next $24 \mathrm{~h}$, returned to normal range. They suggested that NORS may have more than one effect as an alternative to antibiotics. It is effective against NORS drug-resistant mastitis infections and reaches shorter cleaning times. Therefore, it has been reported that its use can be safe (Regev et al., 2018). Cardozo et al. (2014) were prepared NO-releasing polymeric particles composed or alginate/chitosan or chitosan/sodium tripolyphosphate against Staphylococcus aureus and Escherichia coli and used to encapsulate mercaptosuccinic acid (MSA), which is a thiol-containing molecule. The results show that NO-releasing polymeric particles might be used to combat bacteria in treating and preventing bovine mastitis. 


\section{CONCLUSION}

Subclinical mastitis negatively affected milk production, composition and milk quality in cows and cause significant economic losses. To reduce these negative effects of mastitis, it is necessary to understand inflammation reactions and identify and target the mediators involved in inflammation. In this sense, the study presented is a basic feature and it has been observed that NO levels change without changing the acute phase proteins and oxidant and antioxidant capacity levels. Consequently, NO is an important mediator in subclinical mastitis as a potential target of therapeutic strategies and can be evaluated in alternative diagnosis in plasma.

\section{REFERENCES}

Alba DF, da Rosa G, Hanauer D, Saldanha TF, Souza CF, Baldissera MD, Da Silva AS, 2019. Subclinical mastitis in Lacaune sheep: Causative agents, impacts on milk production, milk quality, oxidative profiles and treatment efficacy of ceftiofur. Microbial Pathogenesis, 137: 103732.

Atakisi O, Oral H, Atakisi E, Merhan O, Pancarci SM, Ozcan A, Marasli S, Polat B, Colak A, Kaya S, 2010. Subclinical mastitis causes alterations in nitric oxide, total oxidant and antioxidant capacity in cow milk. Research in Veterinary Science, 89(1): 10-13.

Basu S, Eriksson M, 2001. Retinol palmitate counteracts oxidative injury during experimental septic shock. Annals of the Academy of Medicine, 30: 265-269.

Beckman JS, Beckman TW, Chen J, Marshall PA, Freeman BA, 1990. Apparent hydroxyl radical production by peroxynitrite: implications for endothelial injury from nitric oxide and superoxide. Proceedings of the National Academy of Sciences, 87: 1620-24.

Bhosale RR, Osmani RA, Ghodake PP, Shaikh SM, Chavan SR, 2014. Mastitis: an intensive crisis in veterinary science. International Journal of Pharma Research and Health Sciences, 2: 96-103.

Bouchard L, Blais S, Desrosiers C, Zhao X, Lacasse P,1999. Nitric oxide production during endotoxin-induced mastitis in the cow. Journal of Dairy Science, 82(12): 2574-2581.

Brito M, González FD, Ribeiro LA, Campos R., Lacerda, L, Barbosa PR, Bergmann, G, 2006. Composição do sangue e do leite em ovinos leiteiros do sul do Brasil: variações na gestação e na lactação. Ciência Rural, 36 (3): 942-948.

Cardozo VF, Lancheros CA, Narciso AM, Valereto EC, Kobayashi RK, Seabra AB, Nakazato, G, 2014. Evaluation of antibacterial activity of nitric oxide-releasing polymeric particles against Staphylococcus aureus and Escherichia coli from bovine mastitis. International Journal of Pharmaceutics, 473(1-2): 20-29.

Contreras-Aguilar MD, Monkeviciene I, Ceron JJ, Silinskas I, Vallejo-Mateo PJ, Tecles F, Zelvyte R, 2019. Biochemical changes in saliva of cows with inflammation: A pilot study. Research in Veterinary Science, 124: 383-386.

Conzuelo F, Campuzano S, Gamella M, Pinacho DG, Reviejo AJ, Marco MP, Pingarrón JM, 2013. Integrated disposable electrochemical immunosensors for the simultaneous determination of sulfonamide and tetracycline antibiotics residues in milk. Biosensensors and Bioelectronics, 50: 100-105.

Cortinhas CS, Tomazi T, Zoni MSF, Moro E, Santos, MV, 2016 Randomized clinical trial comparing ceftiofur hydrochloride with a positive control protocol for intramammary treatment of nonsevere clinical mastitis in dairy cows. Jounal Dairy Science, 99 (7): 5619-5628.

Cristina M, Melo RT, Mendonça EP, Coelho LR, Rossi DA, 2010. Uso de ceftiofur em vacas leiteiras e sua excreção no leite, PUBVET. Londrina 4 (33): 931-937.

Enger BD, 2019. Invited Review: Reevaluating how mastitis reduces milk yield: Discussion of competitive substrate utilization. Applied Animal Science, 35(4): 408-415.

Erel O, 2005. A new automated colorimetric method for measuring total oxidant status. Clinical Biochemistry, 38: 1103-1111. 
Giannini EG, Testa R, Savarino V, 2005. Liver enzyme alteration: a guide for clinicians. Canadian Medical Association Journal, 172(3): 367-379.

Ilgun T, Dalgınlı KY, Gulmez C, Atakisi O, 2016. Changes in the levels of liver HSP70, plasma nitric oxide and antioxidative system in experimentally induced endotoxemia mouse model and the role of reduced glutathione. Turkish Journal of Biology, 40: 1272-1277.

Ingman WV, Glynn DJ, Hutchinson MR, 2014. Inflammatory mediators in mastitis and lactation insufficiency. Journal of Mammary Gland Biology and Neoplasia, 19(2):161-167.

Lee M, Rey K, Besler K, Wang C, Choy J, 2017. Immunobiology of nitric oxide and regulation of inducible nitric oxide synthase. Macrophages, 62: 181-207

Lykkesfeldt J, Svendsen O, 2007. Oxidants and antioxidants in disease: oxidative stress in farm animals. Veterinary Journal, 173: 502-511.

Miranda KM, Espey MG, Wink DA, 2001. A rapid, simple spectrophotometric method for simultaneous detection of nitrate and nitrite. Nitric Oxide: Biology and Chemistry, 5: 62-71.

Nedić S, Vakanjac S, Samardžija M, Borozan S, 2019. Paraoxonase 1 in bovine milk and blood as marker of subclinical mastitis caused by Staphylococcus aureus. Research in Veterinary Science, 125: 323-332.

Neto AE, Júnior FG, Santos JCA, Silva LCA, Matos RAT, 2015. Evaluation of antibiotic residues in milk samples from cows after dry cow therapy. Arquivos do Instituto Biológico, 82: 1-4.

Osman KM, Hassan HM, Ibrahim IM, Mikhail MM, 2010. The impact of staphylococcal mastitis on the level of milk IL-6, lysozyme and nitric oxide. Comparative immunology, microbiology and infectious diseases, 33(1): 85-93.

Piotrowska-Tomala KK, Bah MM, Jankowska K, Lukasik K, Warmowski P, Galvao AM, Skarzynski DJ, 2015. Lipopolysaccharides, cytokines, and nitric oxide affect secretion of prostaglandins and leukotrienes by bovine mammary gland during experimentally induced mastitis in vivo and in vitro. Domestic Animal Endocrinology, 52:90-99.

Pryor WA, Squadrito GL, 1995. The chemistry of peroxynitrite: a product from the reaction of nitric oxide with superoxide. American Journal of Physiology, 268: 699-722.

Regev G, Martins J, Sheridan MP, Leemhuis J, Thompson J, Miller C, 2018. Feasibility and preliminary safety of nitric oxide releasing solution as a treatment for bovine mastitis. Research in Veterinary Science, 118: 247-253.

Seegers H, Fourichon C, Beaudeau F, 2003. Production effects related to mastitis and mastitis economics in dairy cattle herds. Veterinary Research. 34: 475-491.

Silanikove N, Merin U, Shapiro F, Leitner G, 2014. Subclinical mastitis in goats is associated with upregulation of nitric oxide-derived oxidative stress that causes reduction of milk antioxidative properties and impairment of its quality. Journal of Dairy Science, 97(6): 3449-3455.

Simontacchi M, Garcia-Mata C, Bartoli Cg, Santa-Maria Ge, Lamattina L, 2013. Nitric oxide as a key component in hormone-regulated processes. Plant Cell Reports, 32(6): 853-866.

Tothova CS, Nagy O, Kovac G, 2014. Acute phase proteins and their use in the diagnosis of diseases in ruminants: a review. Veterinarni Medicina, 59(4).

Turk R, Piras C, Kovačić M, Samardžija M, Ahmed H, De Canio M, ... Roncada P, 2012. Proteomics of inflammatory and oxidative stress response in cows with subclinical and clinical mastitis. Journal of Proteomics, 75(14): 4412-4428.

Zduńczyk S. Janowski T, 2020. Bacteriophages and associated endolysins in therapy and prevention of mastitis and metritis in cows: Current knowledge. Animal Reproduction Science, 106504. 